\title{
Itaconic Acid Fermentation by a Yeast Belonging to the Genus Candida
}

\author{
Takeshi Tabuchi, Teruhide Sugisawa,* Tsuguo Ishidori, \\ Tadaatsu NaKahara and Junta SugIYama ${ }^{\dagger}$ \\ Institute of Applied Biochemistry, The University of Tsukuba, Ibaraki 305, Japan \\ ${ }^{\dagger}$ Central Research Laboratories, Mitsubishi Chemical Industries, Yokohama 227, Japan
}

Received September 17, 1980

\begin{abstract}
Many yeasts were isolated from natural sources in the tropics and subtropics by enrichment culture technique, using medium which contained a surfactant. The medium was acidified with citric acid. A strain S-10 belonging to the genus Candida was found to produce itaconic acid. Under suitable conditions in shake culture, a mutant derived from this strain produced the acid at about $35 \%$ yield on the basis of glucose supplied.
\end{abstract}

The isolation of useful yeasts was tried from natural sources of the tropics and the subtropics, and many yeasts were easily obtained by use of a selective medium. The examination of their metabolites revealed that one strain of them produced itaconic acid in shake culture.

Itaconic acid is known to be produced from sugar by filamentous fungi, such as Aspergillus itaconicus, ${ }^{1)}$ Asp. terreus, ${ }^{2)}$ Ustilago zeae ${ }^{31}$ and Helicobasidium mompa, ${ }^{4}$ and has been produced commercially by Asp. terreus. The acid, however, is not known to be produced by any yeasts.

This paper describes the method and the results of the selective enrichment culture in the isolation of yeasts, the identification of the strain producing itaconic acid, the isolation of mutants and factors affecting the production of the acid by a mutant derived from the strain.

\section{MATERIALS AND METHODS}

Microorganisms. Strain $\mathrm{S}-10$ and its mutants were employed. Yeast strains stocked in our laboratory were also used in this study. They were all maintained on potato-dextrose agar.

Growth test in acidic medium. The effect of addition of organic acids on the growth of yeasts were tested in

* Present address: Department of Microbiology and Chemotherapy, Nippon Roshe Research Center, Kamakura 247, Japan.
Monod's test tubes containing $8 \mathrm{ml}$ of the medium composed of glucose $2 \%$, yeast extract $0.5 \%$ and one of different organic acids $1 \%$. The test tubes were inoculated with one drop of cell suspensions prepared from potato-dextrose agar slants and the cultures were incubated at $26^{\circ} \mathrm{C}$ on a Monod's shaker. Growth was measured as turbidity at $580 \mathrm{~nm}$ with a ShimadzuBausch \& Lomb Spectronic 20 colorimeter.

Isolation of yeasts by use of selective medium. Natural sources were added into test tubes containing $8 \mathrm{ml}$ of the selective medium composed of glucose $10 \%$, yeast extract $0.3 \%$, citric acid monohydrate $1 \%$ and 2 drops of Tween 40 per liter. The cultures were incubated statically at $30^{\circ} \mathrm{C}$ for 3 to 5 days. If surface growth was observed on the culture, the test tubes were shaken to sink cells growing on surface and then the incubation was continued. When turbidity was observed in the test tubes, the culture broth was streaked on agar medium composed of glucose $10 \%$, yeast extract $0.5 \%$, $\mathrm{KH}_{2} \mathrm{PO}_{4} 0.1 \%, \mathrm{MgSO}_{4} \cdot 7 \mathrm{H}_{2} \mathrm{O} 0.05 \%, \mathrm{CaCO}_{3} 0.5 \%$ and agar $2 \%$. Colonies dissolving $\mathrm{CaCO}_{3}$ were isolated and stocked on potato-dextrose agar.

Shake culture. In screening tests of fermentation products, cells grown on potato-dextrose agar slants were inoculated into $25 \mathrm{ml}$ of the medium composed of glucose $10 \%, \mathrm{NH}_{4} \mathrm{Cl} 0.3 \%, \mathrm{KH}_{2} \mathrm{PO}_{4} 0.05 \%, \mathrm{MgSO}_{4}$. $7 \mathrm{H}_{2} \mathrm{O} 0.05 \%$, yeast extract $0.1 \%$ and $\mathrm{CaCO}_{3}$ (sterilized separately) 3 to $5 \%$ in $300-\mathrm{ml}$ Erlenmeyer flasks, and incubated for 7 days at $26^{\circ} \mathrm{C}$ on a rotary shaker (220 rpm).

For the cultural studies of itaconic acid production, seed culture was prepared by the same method as used in the screening tests except for the incubation period of 2 days. The seed culture $(1 \mathrm{ml})$ was transferred to production media contained in $500-\mathrm{ml}$ Erlenmeyer flasks. The flasks were shaken on the rotary shaker at $26^{\circ} \mathrm{C}$. 
Identification of strain $S-10$. Taxonomic studies on the isolated yeast, strain S-10, were carried out according to the methods described by Lodder. ${ }^{5)}$ The formation of carotenoid pigments was confirmed by the procedure of Hasegawa et $a l .^{6)}$ Urease test was performed by using Christensen's urea agar (Seeliger ${ }^{7}$ ), and the reactions were recorded after 5 days incubation at $25^{\circ} \mathrm{C}$. The presence of extracellular deoxyribonuclease (DNase) was determined by the procedure of Cazin et al. ${ }^{8)}$; DNase Test Agar (Difco) was supplemented with $1 \%$ yeast extract (Difco) and $1 \%$ glucose (Sen and Komagata ${ }^{9}$ ).

Isolation of mutants. Mutants possessing high productivity of itaconic acid were derived from strain S-10 as follows. The cells of strain S-10 grown on potatodextrose agar were suspended in $0.05 \mathrm{M}$ phosphate buffer (pH 6.5). To $30 \mathrm{ml}$ of this suspension (about $1 \times 10^{8}$ cells per $\mathrm{ml}$ ) was added $12 \mathrm{mg}$ of $N$-methyl-N'-nitro$\mathrm{N}$-nitrosoguanidine (NTG) and the mixture was incubated at $26^{\circ} \mathrm{C}$ for $30 \mathrm{~min}$. The cells were washed twice with the phosphate buffer and spread on the same agar medium. After incubation at $26^{\circ} \mathrm{C}$ for 3 to 5 days, colonies dissolving rapidly $\mathrm{CaCO}_{3}$ in the agar medium were isolated.

Analytical methods. The products in the culture broths were mainly characterized by paper chromatography. After the culture broths had been made acid to Tropaeolin $\mathrm{OO}$ with $6 \mathrm{~N} \mathrm{HCl}$, the acidic broths were spotted on Toyo-Roshi No. 51 paper and the paper was air-dried at room temperature. Ascending chromatography was accomplished with ethyl acetate-acetic acidwater (50:12:10) as a solvent. Products were located on paper chromatograms by spraying $0.2 \%$ bromophenol blue in ethanol and freshly prepared $0.5 \%$ $\mathrm{KMnO}_{4}$ solution.

Itaconic acid was determined by gas liquid chromatography under the same conditions as described previously, $\left.{ }_{10}\right)$ with the exception of program rate $\left(5^{\circ} \mathrm{C}\right.$ per $\mathrm{min}$ ) for linear temperature programmed analysis.

\section{RESULTS}

\section{Isolation of yeasts}

The growth response of various yeasts to media acidified with different organic acids was examined in order to develop the culture medium to make yeasts selectively grow and to prevent most bacteria from growing. Figure 1 shows one example of the experimental results. Citric acid did not have any inhibitory effect on the growth rate of Saccharomycopsis lipolytica IFO 1659, although it prolonged the lag phase of the growth. On the other hand, acetic

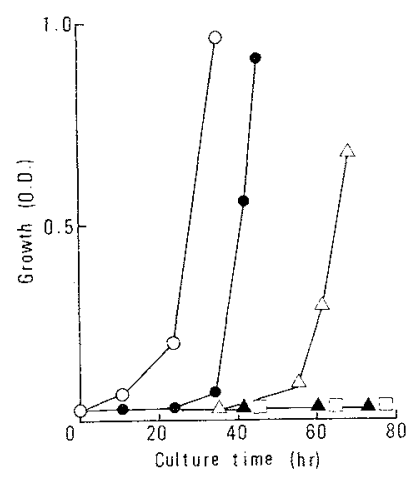

Frg. 1. Growth Response of Saccharomycopsis lipolytica IFO 1659 to Media Acidified with Different Organic Acids.

Cells of Saccharomycopsis lipolytica IFO 1659 grown on potato-dextrose agar were washed, inoculated to Monod's test tubes containing each $8 \mathrm{ml}$ of the media composed of glucose $2 \%$, yeast extract $0.5 \%$ and one of the indicated organic acids $1 \%$, and incubated with shaking at $26^{\circ} \mathrm{C}$.

$\mathrm{O}-\mathrm{O}$, control; $-\bullet$, citric acid; $\triangle-\triangle$, itaconic acid;

$\triangle-\mathbf{\Lambda}$, acetic acid; $\square-\square$, propionic acid.

and propionic acids inhibited completely the growth of the yeast. The similar effect of the organic acids on growth was also observed in 10 other yeast strains tested. The results showed that citric acid was suitable for lowering the $\mathrm{pH}$ of the selective medium.

The addition of a surfactant, Tween 40 , to the acidified medium made easy to disperse natural sources and also prevented in part the surface growth of filamentous fungi in static culture. After the selective enrichment culture, bacterial colonies on plate culture were few in number and were usually distinguished by their transluscent appearance from yeast colonies. About 140 strains, thus, were newly isolated from the natural sources of the tropics and the subtropics.

\section{Screening of yeasts producing organic acids}

Newly isolated strains were screened for their productivity of organic acids from glucose.

Strain S-10 which was isolated from the exudate of a tree at Ishigaki Island near Taiwan was selected for a producer of an organic acid. The acid gave a spot $(R f=0.87)$ on the paper chromatogram and was also easily located by 
spraying $\mathrm{KMnO}_{4}$ solutions. This $R f$ value agreed closely with that of an authentic sample of itaconic acid.

\section{Isolation and identification of the acid}

Strain S-10 was cultured for 7 days in twenty Erlenmeyer flasks containing the screening medium. The culture broths were collected (500 ml), acidified to $\mathrm{pH} 1.8$ with $4 \mathrm{~N} \mathrm{H}_{2} \mathrm{SO}_{4}$ and filtered through Kieselguhr layer. The filtrate was extracted twice with ether. Removal of the ether left a solid mass $(2.5 \mathrm{~g})$, which gave white crystals, mp $164 \sim 165^{\circ} \mathrm{C}$, after recrystallization from water. This acid gave no depression of melting point on admixture with the authentic sample of itaconic acid and it had an identical infrared absorption spectrum with that of the sample of itaconic acid.

\section{Identification of the yeast, strain $S-10$}

Table I shows the characteristic of this strain. From these characteristics, strain S-10 was identified as Candida sp.

\section{Induction of mutants \\ Induction of mutants was tried because itaconic acid productivity of strain S-10 was not much improved by the change of cultural conditions. The productivities of most mutants selected as higher producers were unstable and sometimes decreased on preservation. After successive mutagenic treatments of mutants, a stable mutant, strain B-1, was obtained, which produced the acid in about $35 \%$ yield.}

Table I. Description of Strain S-10

Growth in malt extract: After 3 days at $25^{\circ} \mathrm{C}$ cells are oval, elliptical or fusiform $5-10 \times 2-4 \mu \mathrm{m}$, single, in pairs or in short chains; septate hyphae are present; no exudate in the medium. A pellicle and sediment are formed. Occasionally single buds arose from very short sterigma-like spicules of the cells.

Growth on malt agar: After 3 days at $25^{\circ} \mathrm{C}$ the streak culture is flesh-colored, smooth, glistening, entire at the margin; after 10 days it is flesh-colored to pale yellow due to carotenoid, dull, smooth to wrinkled, mucous to membranous, with a filamentous fringe.

Dalmau plate culture on Bacto-yeast morphology agar (Difco) and corn meal agar: True mycelium, pseudomycelium and blastospores are formed. Blastospores are ovoid or fusiform and are present singly or in short chains. Occasionally single buds arose from short sterigma-like spicules of the single cells and hyphal cells often arranged in ramified chains. No droplet mechanism was observed with the sterigma-like spicules; when the buds detached, the spicules remained attached to the mother cell.

Sporulation: No ascospores were observed on V8-agar, carrot- and potato-wedges, potatodextrose agar, Gorodkowa agar, malt agar, and corn meal agar.

Neither clamp connections nor other spores (i.e., teliospores, ballistospores, arthrospores, endospores, and chlamydospores) have been observed.

Carotenoid pigments: Present; the absorption maximum was at $450 \mathrm{~nm}$ (with two shoulders at 420 and $480 \mathrm{~nm}$ ).

Fermentation: Glucose (-), Galactose (-), Sucrose (-), Maltose (-), Lactose (-), Raffinose (-).

Assimilation: Glucose $(+)$, Galactose $(+)$, L-Sorbose $(+)$, Sucrose $(+)$, Maltose $(+)$, Cellobiose (weak), Trehalose $(+)$, Lactose $(+)$, Melibiose $(-)$, Raffinose $(+)$, Melezitose $(+)$, Inulin $(+)$, Soluble starch $(+)$, D-Xylose $(+)$, L-Arabinose $(+)$, D-Arabinose (-), D-Ribose (-), L-Rhamnose ( - ), Ethanol $(+)$, Glycerol $(+)$, Erythritol $(+)$, Adonitol $(+)$, Dulcitol $(-)$, Galactitol (-), D-Mannitol $(+)$, $\alpha$-Methyl-D-glucoside $(+)$, Salicin (weak), Succinic acid $(+)$, Citric acid $(-)$, Inositol $(+)$.

Splitting of arbutin: Negative or weakly positive.

Assimilation of nitrogen compounds: Positive for nitrate and ammonium sulphate, but negative for nitrite.

Growth in vitamin-free medium: Positive.

Formation of starch-like compounds: Negative.

Urease: Present.

Extracellular DNase: Present.

Growth at $37^{\circ} \mathrm{C}$ : Negative.

Habitat: Isolated from the exudate of an unidentified Japanese tree, Ishigaki Island, Okinawa Prefecture, T. Ishidori, viii. 1974, strain S-10. 
Factors affecting the production of itaconic acid by the mutant

Preliminary experiments showed that the production of itaconic acid decreased at low $\mathrm{pH}$ (below about 3) and nitrogen sources affected acid production. Table II shows the effects of nitrogen sources and a neutralizing agent, $\mathrm{CaCO}_{3}$, on acid production. When acidic nitrogen sources such as $\mathrm{NH}_{4} \mathrm{Cl}$ and $\left(\mathrm{NH}_{4}\right)_{2} \mathrm{SO}_{4}$ were employed, the addition of neutralizing agent such as $\mathrm{CaCO}_{3}$ was needed for acid production. On the other hand, alkaline nitrogen sources such as $\mathrm{NaNO}_{3}$ and $\mathrm{KNO}_{3}$ resulted in high acid yields without neutralizing agents. Keeping the $\mathrm{pH}$ of media above about 3 was important for acid production.

Table II. EfFects of Nitrogen Sources and Calcium Carbonate on Itaconic Acid Production by a Mutant, Strain B-1

The mutant was cultured at $26^{\circ} \mathrm{C}$ for 5 days in $300-\mathrm{ml}$ Erlenmeyer flasks containing each $25 \mathrm{ml}$ of the medium composed of glucose $10 \%$, the indicated nitrogen source $420 \mathrm{mg}$ as nitrogen per liter, $\mathrm{KH}_{2} \mathrm{PO}_{4}$ $0.02 \%, \mathrm{MgSO}_{4} \cdot 7 \mathrm{H}_{2} \mathrm{O} 0.05 \%$ and $\mathrm{CaCO}_{3} 5 \%$.

\begin{tabular}{cccc}
\hline $\begin{array}{c}\text { Nitrogen } \\
\text { source }\end{array}$ & $\begin{array}{c}\mathrm{CaCO}_{3} \\
(\%)\end{array}$ & \multicolumn{2}{c}{ Final pH Itaconic acid } \\
of medium & $(\mathrm{mg} / \mathrm{ml})$ \\
\hline $\mathrm{NH}_{4} \mathrm{Cl}$ & 0 & 2.2 & 2 \\
& 5 & 6.5 & 35 \\
$\mathrm{NaNO}_{3}$ & 0 & 3.3 & 33 \\
& 5 & 6.8 & 30 \\
\hline
\end{tabular}

\section{DISCUSSION}

The present yeast exhibited characters of the form genus Candida Berkhout circumscribed by $N$. van Uden and H. Buckley in "The Yeasts", with the exception to pigment formation and bud formation with a sterigma-like spicule. The morphological and physiological properties shown by strain $\mathrm{S}-10$ are most similar to those of Candida fusiformata, recently described by Buhagiar ${ }^{11}$ from cabbages and cauliflowers in U.K., in the known yeast species. According to Buhagiar's description, C. fusiformata is delimited by the following characteristics: streak cultures on certain media are lightly tinged with pink (however, no attempt was made to determine whether the pigment formation is due to carotenoid); buds are often formed from acicular or ampulliform spicules; it has no fermentative activity; it assimilates inositol, erythritol and nitrate, and lacks amyloid material; no teleomorph has been observed. In the present study, the presence or absence of the formation of carotenoid pigments in C. fusiformata was determined based on the method described by Hasegawa et al. ${ }^{B}$ ) The absorption pattern of carotenoid pigments of C. fusiformata CBS 6951 (type strain) was agreed well with that of Candida sp. strain $\mathrm{S}-10$; similarly its absorption maximum was at $450 \mathrm{~nm}$ (with two shoulders at 420 and $480 \mathrm{~nm}$ ). Our yeast differs from C.fusiformata in ability to assimilate lactose, D-galactose and sol. starch, and in failure to assimilate citrate. Differences between $C$. fusiformata and its similar taxa have been fully discussed by Buhagiar. ${ }^{11)}$

Sen and Komagata ${ }^{97}$ divided yeast species into four groups on the basis of combination of the ability to produce urease and extracellular DNase. This yeast produces both urease and extracellular DNase, and therefore, belongs to Group 1 categorized by them. ${ }^{9)}$ They $^{9}$ have strongly suggested the relation of four taxa of Candida (C. bogoriensis, C. curvata, C. diffluens and C. humicola) in Group 1 to the basidiomycetous yeasts. We found here its pigment formation, budding on sterigma-like spicules and ability to produce both urease and extracellular DNase, which may suggest a possible phylogenetic relationship between our yeast and the basidiomycetous yeasts, particulary anamorphs of the Ustilaginales.

However, we reserve our opinion concerning the taxonomic status of the present yeast as a species of Candida until comparative observations between strain $\mathrm{S}-10$ and $C$. fusiformata can be done, range of variation assessed, and its identity elucidated.

Itaconic acid is known as a metabolite of several filamentous fungi and has been commercially produced by Asp. terreus, but the present findings still may imply industrial possibilities because the submerged cultures of yeasts, in general, are easy to control than 
those of filamentous fungi and the present yeast can produce the acid from raw materials such as cane molasses.

Acknowledgments. One of the authors (J.S.) wishes to thank Dr. L. Rodrigues de Miranda, Centraalbureau voor Schimmelcultures, Delft, for providing the type strain of Candida fusiformata, and Miss M. Sakimoto for her technical assistance.

\section{REFERENCES}

1) K. Kinoshita, J. Chem. Soc. Jpn., 50, 583 (1929).

2) C. T. Calam, A. E. Oxford and H. Raistrick, Biochem. J., 33, 1488 (1955).

3) R. H. Haskins, J. A. Thorn and B. Boothroyd,
Can. J. Microbiol., 1, 749 (1955).

4) T. Araki, Y. Yamazaki and N. Suzuki, Bull. Natl. Inst. Agric. Sci. Jpn., Ser. C, No. 8, 53 (1957).

5) J. Lodder, "The Yeasts, a taxonomic study," 2nd Ed., North-Holland Publishing Co., Amsterdam and London, 1970.

6) T. Hasegawa, I. Banno and S. Yamauchi, J. Gen. Appl. Microbiol. (Tokyo), 6, 196 (1960).

7) H. P. R. Seeliger, J. Bacteriol., 72, 127 (1956).

8) J. Cazin, Jr., T. R. Kozel, D. M. Lupan and W. R. Burt, J. Bacteriol., 100, 760 (1969).

9) K. Sen and K. Komagata, J. Gen. Appl. Microbiol. (Tokyo), 25, 127 (1979).

10) T. Tabuchi and N. Serizawa, Agric. Biol. Chem., 39, 1049 (1975).

11) R. W. M. Buhagiar, J. Gen. Microbiol., 110, 91 (1979). 